\title{
Acute effects of a selective cannabinoid- 2 receptor agonist on neuroinflammation in a model of traumatic brain injury.
}

\author{
Melanie B Elliott \\ Department of Neurological Surgery, Thomas Jefferson University \\ Ronald F Tuma \\ Department of Physiology, Temple University Medical School \\ Peter S Amenta \\ Department of Neurological Surgery, Thomas Jefferson University \\ Mary F Barbe \\ Department of Anatomy and Cell Biology, Temple University Medical School \\ Jack I Jallo \\ Department of Neurological Surgery Thomas Jefferson University \\ Follow this and additional works at: https://jdc.jefferson.edu/neurosurgeryfp \\ Part of the Medical Neurobiology Commons, Neurology Commons, and the Surgery Commons \\ Let us know how access to this document benefits you
}

\section{Recommended Citation \\ Elliott, Melanie B; Tuma, Ronald F; Amenta, Peter S; Barbe, Mary F; and Jallo, Jack I, "Acute effects of a selective cannabinoid-2 receptor agonist on neuroinflammation in a model of traumatic brain injury." (2011). Department of Neurosurgery Faculty Papers. Paper 16. https://jdc.jefferson.edu/neurosurgeryfp/16}

This Article is brought to you for free and open access by the Jefferson Digital Commons. The Jefferson Digital Commons is a service of Thomas Jefferson University's Center for Teaching and Learning (CTL). The Commons is a showcase for Jefferson books and journals, peer-reviewed scholarly publications, unique historical collections from the University archives, and teaching tools. The Jefferson Digital Commons allows researchers and interested readers anywhere in the world to learn about and keep up to date with Jefferson scholarship. This article has been accepted for inclusion in Department of Neurosurgery Faculty Papers by an authorized administrator of the Jefferson Digital Commons. For more information, please contact: JeffersonDigitalCommons@jefferson.edu. 


\title{
Acute Effects of a Selective Cannabinoid-2 Receptor Agonist on Neuroinflammation in a Model of Traumatic Brain Injury
}

\author{
Melanie B. Elliott, ${ }^{1}$ Ronald F. Tuma, ${ }^{2}$ Peter S. Amenta, Mary F. Barbe, ${ }^{3}$ and Jack I. Jallo ${ }^{1}$
}

\begin{abstract}
Proposed therapeutic strategies for attenuating secondary traumatic brain injury (TBI) include modulation of acute neuroimmune responses. The goal of this study was to examine the acute effects of cannabinoid-2 receptor $\left(\mathrm{CB}_{2} \mathrm{R}\right)$ modulation on behavioral deficits, cerebral edema, perivascular substance $\mathrm{P}$, and macrophage/microglial activation in a murine model of TBI. Thirty male C57BL/ 6 mice underwent sham surgery, or cortical contusion impact injury (CCI). CCI mice received vehicle or the $\mathrm{CB}_{2} \mathrm{R}$ agonist 0-1966 at 1 and $24 \mathrm{~h}$ after injury. Performance on the rotarod, forelimb cylinder, and open-field tests were evaluated before and at $48 \mathrm{~h}$ after sham or CCI surgery. Cerebral edema was evaluated using the wet-dry weight technique. Immunohistochemical analysis was used to examine changes in substance $\mathrm{P}$ and macrophage/microglia-specific Iba1 protein immunoreactivity. Locomotor performance and exploratory behavior were significantly improved in mice receiving 0-1966 ( $\mathrm{CB}_{2} \mathrm{R}$ agonist) compared to vehicle-treated mice. Significant reductions were found for cerebral edema, number of perivascular areas of substance P immunoreactivity, and number of activated macrophages/ microglial cells in the injured brains of 0-1966-treated mice compared to vehicle-treated mice. The findings show that the effects of the $\mathrm{CB}_{2} \mathrm{R}$ agonist 0-1966 on edema, substance $\mathrm{P}$ immunoreactivity, and macrophage/microglial activation, were associated with recovery of acute motor and exploratory deficits. This study provides evidence of acute neuroprotective effects derived from selective $\mathrm{CB}_{2} \mathrm{R}$ activation that may represent an avenue for further development of novel therapeutic agents in the treatment of TBI.
\end{abstract}

Key words: controlled cortical impact injury; glial response; inflammation; neurotransmitters; traumatic brain injury

\section{Introduction}

$\mathbf{T}$ HE ENORMITY of the problem of traumatic brain injury (TBI) cannot be overstated, as over 1.7 million Americans are affected annually, with many suffering fatal or permanently disabling injuries. Unfortunately, despite the well-known deleterious effects of TBI, medical and surgical interventions remain limited, and advancements in treatment have been relatively non-existent. TBI is a broad term that envelops a dynamic series of overlapping phases. Primary injury occurs at the time of the insult and is not amenable to treatment. It does, however, set in motion a complex constellation of cellular and biochemical processes. The end result, secondary injury, evolves over the subsequent hours to days, and manifests as cerebral edema, increased intracranial pressure, ischemia, and eventual infarction. Early edema formation, in the first $72 \mathrm{~h}$ after cerebral contusions, contributes to intracranial hypertension and clinical decline or fatality. This time period is a critical window for interrupting secondary injury mechanisms (Kawamata and Katayama, 2007). Cerebral edema formation is due in part to neurogenic inflammatory mechanisms in which the release of substance $\mathrm{P}$, a potent long-lasting vasoactive tachykinin, is believed to be the predominant mediator (Donkin et al., 2007, 2009). Substance P antagonists are currently proposed as a therapeutic approach for TBI (Vink and van den Heuvel, 2010). However, in a rat model of sciatic nerve section, an unfortunate side effect of 2 weeks of treatment with an antagonist against the key substance $P$ receptor (neurokinin-1) is widespread bone resorption (Kingery et al., 2003). This latter

\footnotetext{
${ }^{1}$ Department of Neurological Surgery, Thomas Jefferson University, Philadelphia, Pennsylvania.

${ }^{2}$ Department of Physiology, and ${ }^{3}$ Department of Anatomy and Cell Biology, Temple University Medical School, Philadelphia, Pennsylvania.
} 
finding suggests that other effective therapies need to be explored.

In the wake of TBI, neuroimmune-inflammatory responses are important for repair and possible regeneration of the injured central nervous system (CNS), but also contribute to secondary injury cascades that promote continued cellular destruction. Although the dual role of the inflammatory response to CNS injury has been well-characterized, the optimal immunomodulation for improving outcome from TBI remains elusive. Microglial cells, the resident macrophages of the CNS, along with infiltrating macrophages/monocytes from the circulation, represent the predominant mediators of secondary injury. When activated, microglia play a key role in the production of proinflammatory cytokines, phagocytosis, and antigen presentation, all of which contribute to the development of cerebral edema and exacerbation of TBI. In the present study we evaluated the effects of modulating the acute neuroimmune response by selectively targeting receptors for endogenous cannabinoids found predominantly on macrophage/microglia in the injured brain. Interestingly, injury to the CNS, including TBI, increases both the release of endogenous cannabinoids (2-AG and anandamide), and expression of their receptors (Mechoulam and Shohami, 2007; Panikashvili et al., 2001; van der Stelt et al., 2002). The general consensus is that the changes in endocannabinoid and receptor expression in the injured brain are an attempt at self-protection.

Previous studies have described the presence of a specific receptor, cannabinoid-1 receptor $\left(\mathrm{CB}_{1} \mathrm{R}\right)$, as the receptor responsible for inducing the psychoactive effects of $\Delta^{9}$ tetrahydrocannabinol (THC). In 1993, Munro and associates reported a second cannabinoid receptor, cannabinoid-2 receptor $\left(\mathrm{CB}_{2} \mathrm{R}\right)$, in the immune and hematopoietic systems, which was later found to be expressed by microglia and astrocytes in the brain (Gong et al., 2006; Munro et al., 1993;Van Sickle et al., 2005). This second receptor has since been shown to be devoid of psychoactive effects, while possessing potent immunomodulatory and anti-inflammatory properties. At rest, microglial expression of $\mathrm{CB}_{2} \mathrm{R}$ is negligible, however, activation, as is seen in TBI, leads to an increase in the expression of the receptor. Evidence is emerging that $C_{2} R$ activation modulates microglial function, resulting in predominantly anti-inflammatory and neuroprotective effects after injury. These findings make the endocannabinoid system, particularly $\mathrm{CB}_{2} \mathrm{R}$, a potential target for novel therapeutic agents for the treatment of TBI. Therefore, the main goal of this study was to examine the acute effects of a $\mathrm{CB}_{2} \mathrm{R}$ agonist, 0-1966, on behavioral deficits, cerebral edema, perivascular substance P immunoreactivity, and macrophage/microglial activation, in a murine model of TBI. Our hypothesis was that $\mathrm{CB}_{2} \mathrm{R}$ activation will reduce inflammation and provide a neuroprotective effect post-TBI.

\section{Methods}

\section{Experimental design, animal care, and anesthesia}

Prior to initiating any research, the Thomas Jefferson University Institutional Animal Care and Use Committee reviewed and approved the research protocol, and approved the use of male C57BL/ 6 mice from Charles River as experimental animals. Animal care and use was monitored by the University Animal Care and Use Committee to assure compliance with the provisions of federal regulations and the National Institutes of
Health (NIH) Guide for the Care and Use of Laboratory Animals. All animals were housed in the Thomas Jefferson University Laboratory Animal Services Facility, which is accredited by the American Association for the Accreditation of Laboratory Animal Care, and complies with NIH standards.

The animals were deeply sedated with isoflurane throughout the surgical procedures and injury. Thirty-six male C57BL/6 mice (approximately 8 weeks of age and weighing approximately 22-24g) were randomly divided into one of three groups: sham controls $(n=12)$, vehicletreated $(n=13)$, and $0-1966$ treatment $(n=11)$. The $\mathrm{CB}_{2} \mathrm{R}$ agonist 0-1966 (0-1966A) is an analog of bicyclic resorcinols (dimethoxy-resorcinol-dimethylheptyl), a chemical compound structurally similar to cannabidiol, as described by Wiley and associates (2002). This particular analog demonstrated superior $\mathrm{CB}_{2} \mathrm{R}$ selectivity (225-fold) and a high binding affinity for the $\mathrm{CB}_{2} \mathrm{R}(\mathrm{Ki}=22.5 \mathrm{nM})$; it was also shown to have poor affinity for $\mathrm{CB}_{1} \mathrm{R}$ (Wiley et al., 2002). Three naïve mice that did not receive surgery or treatment were also included. Controlled cortical impact (CCI), a well-described model for creating lesions in rodents that are histopathologically similar to human TBI, was used to create a traumatic injury in vehicleand 0-1966-treated mice. Sham controls received a craniotomy without TBI. 0-1966 (BTG Pharmaceuticals, Inc., London, U.K.) and vehicle treatments were injected intraperitoneally at 1 and $24 \mathrm{~h}$ post- injury $(5 \mathrm{mg} / \mathrm{kg}$ doses and a volume of $0.1 \mathrm{~mL} / 10 \mathrm{~g}$ body weight; Zhang et al., 2009a). Our treatment paradigm in the present study was based on dosing and time of administration studies conducted in our models of ischemic brain and traumatic spinal cord injury (Baty et al., 2008; Zhang et al., 2009a). The 0-1966 was dissolved in a pure ethanol:emulphor:saline mixture (1:1:18). Vehicle groups received the same mixture without the cannabinoid agent. All mice were allowed to wake up from anesthesia and kept in separate cages post-operatively with unrestricted food and water. The animals were euthanized with a lethal dose of sodium pentobarbital for post-mortem histological analysis. A goal of this study was to examine the effects of a $C_{2} R$ agonist on cerebral edema and neurogenic inflammation. Therefore, a 48-h post-injury time point was chosen for histological assessments, since this is when cerebral edema has been shown to peak after CCI injury, with subsequent resolution of edema between 4 and 7 days after injury (Baskaya et al., 2000; Elliott et al., 2008b).

\section{Traumatic brain injury}

TBI was produced using a CCI injury model as described previously by our laboratory (Elliott et al., 2007, 2008b, 2009c), and modified for mice (Onyszchuk et al., 2007; Saatman et al., 2006). The mice were anesthetized with isoflurane $(5 \%$ induction and $2 \%$ maintenance). To ensure aseptic technique, the heads were shaved using electric clippers, and povidoneiodine and alcohol were applied prior to incision. Thermistors were implanted into the temporalis muscle and rectum in order to monitor and maintain brain and core temperatures at $37 \pm 0.5^{\circ} \mathrm{C}$. The head was fixed in a stereotaxic frame, and a high-speed drill was used to create a right-sided 4-mm craniotomy centered between the bregma and the lambda, thus exposing the sensorimotor cortex. Care was taken to leave the dura intact and the bone flap was removed. TBI was produced using an electromagnetic stereotaxic impactor with a 3-mm- 
diameter rounded aluminum tip. TBI was produced using the predetermined parameters of $1.0 \mathrm{~mm}$ depth, $3.0 \mathrm{~m} / \mathrm{sec}$ velocity, and 100 msec contact time. Following injury, the bone flap was replaced, sealed with bone wax, and the skin was sutured closed with 6-0 black silk sutures.

\section{Behavioral testing}

Behavioral tests were performed on 7 sham controls, 10 vehicle-treated, 10 0-1966-treated, and 3 naïve mice that did not receive surgery or treatment. Naïve behavioral test results were also collected from the vehicle- and 0-1966-treated mice. A rotarod test was included to fully evaluate the impact on locomotion. A Rotamex 4/5 (Columbus Instruments, Columbus, $\mathrm{OH})$ consists of a rotating horizontal cylinder $(7 \mathrm{~cm}$ diameter) divided into 9.5-cm-wide lanes. The mouse was placed on the cylinder in a direction that required forward locomotion to avoid falling. Gradual acceleration occurs from a speed of 12-35 rpm, and the latencies to fall are detected by a photobeam circuit over three trials. Results were reported as mean percentage of baseline latencies \pm standard error of the mean (SEM) to account for individual baseline differences in rotarod performance.

A cylinder test was used to test forelimb motor function as described by Onyszchuk and colleagues (Baskin et al., 2003; Onyszchuk et al., 2007). The apparatus consisted of a 10-cmdiameter clear acrylic glass cylinder. Forelimb usage was observed for two 5-min trials for up to 20 rears per trial. The number of forelimb placements on the cylinder wall using both left and right (B), right only (R), or left only (L) forelimbs was recorded. The results are reported as mean percentage of baseline usage of the affected (left) forelimb \pm SEM. Any animals showing right-handedness during baseline testing were excluded from this test, as an injury to the right cortex in righthanded animals would not cause a change in the left forelimb use.

Open-field testing was used to assess the activity level for natural exploratory behavior, and was conducted in a manner similar to that reported by Wagner and co-workers (Wagner et al., 2007). The mice were placed in the center of a large (50cm-diameter) acrylic glass box equipped for video monitoring. The number of rears in a 5-min observation period for 2 trials was recorded, and results were reported as the mean number of rears \pm SEM.

\section{Cerebral edema measurement}

Cerebral edema was evaluated using the wet-dry weight technique in 7 sham controls, 6 vehicle-treated, and 4 0-1966treated mice, using methods described previously by our laboratory (Elliott et al., 2007, 2008b; Okiyama et al., 2007). Briefly, after administration of a lethal dose of sodium pentobarbital, the brains were quickly removed and cut using a razor blade. One 4-mm coronal section that included the traumatic lesion was collected. Each section was immediately divided into left and right hemispheres at the midline. The left and right hemispheres were sectioned on a frozen glass plate into a cortical region with subcortical regions discarded. The tissue sections were rapidly transferred onto pre-weighed $2.5-\mathrm{cm}^{2}$ aluminum foil squares and placed in a humid chamber to prevent water loss. A wet weight was measured for each tissue sample and foil square. Subsequently, the tissue and foil were dried at $100^{\circ} \mathrm{C}$ for $48 \mathrm{~h}$, and reweighed for the dry weight. The percentage of brain water was calculated as the difference between the wet and dry weights divided by the wet weight. Results are reported as mean percent cerebral edema \pm SEM.

\section{Immunohistochemistry}

Five sham control, 7 vehicle-treated, and 7 0-1966-treated mice were used for immunohistochemistry. The mice were administered a lethal dose of sodium pentobarbital $(120 \mathrm{mg} /$ $\mathrm{kg}$ IP), and underwent cardiac perfusion with heparinized saline, followed by $4 \%$ paraformaldehyde. The brains were quickly removed and post-fixed in $4 \%$ paraformaldehyde for $2 \mathrm{~h}$, at which point they were transferred to $30 \%$ sucrose solution until sinking for cryoprotection. The brains were sectioned coronally with a cryostat at $-24^{\circ} \mathrm{C}(10 \mu \mathrm{m}$ thick, $1: 10$ series, 100 microns between series), mounted, and air dried overnight, then stored at $-20^{\circ} \mathrm{C}$ until staining. Substance P immunostaining was performed using a rabbit anti-substance P primary antibody (cat. no. AB1566; Millipore, Billerica, MA). Macrophages/microglia were stained with rabbitspecific protein ionizing calcium-binding adaptor molecule (lba1) primary antibody (1: 250, cat. no. 019-19741; Wako Chemicals USA, Inc., Richmond, VA). Substance P and Iba1 were visualized with DyLight 549- and 488-conjugated AffiniPure goat anti-rabbit IgG secondary antibodies (Jackson ImmunoResearch, West Grove, PA). 4,6-Diamino-2-phenylindole (DAPI) was used as a nuclear counter-stain for cell counting (cat. no. D3571; Invitrogen, Carlsbad, CA). Negative control staining was performed by omitting the primary antibody or by omitting the secondary antibody. Brain tissues were analyzed using a fluorescence microscope with an $x, y$ motorized stage. This microscope was interfaced with a computerized quantification system (BIOQUANT Image, Nashville, TN), and images were captured using a Retiga EXI cooled camera (QImaging, Surrey, B.C., Canada). To evaluate differences in substance $P$ immunostaining, semi-quantitative methods were used to count the number of sites of substance P immunostaining in the ipsilateral hemisphere around the injury core. Only punctate substance P staining visualized perivascularly and within the parenchyma proximal to cerebral blood vessels were counted. Using an independent random start, the number of substance $\mathrm{P}$ sites were counted under a $40 \times$ objective $(700 \times$ magnification $)$ in three square regions of interest (ROIs) in three sections per brain, and reported as mean \pm SEM. For microglial/macrophage activation, morphological examination and the number of Iba1positive cells were counted using an independent random sampling approach (Elliott et al., 2010; Mouton, 2002). Ipsilateral and contralateral ROIs were randomly selected in areas surrounding the necrotic zone of the injury epicenter using three rectangular boxes $(640 \times 480 \mu \mathrm{m})$ with the BIOQUANT image analysis system under a $20 \times$ objective $(350 \times$ magnification). The number of Iba1-positive cells in three ROIs were counted per section per hemisphere in three adjacent sections per brain through the injury core. To avoid bias in estimating the mean number of Iba1-positive cells, only cells in which the nucleus (DAPI counter-stained) was visible were counted. All cell counts were performed in a blinded manner.

\section{Statistical analysis}

Single-factor group comparisons (naïve, sham, TBI+ vehicle, and TBI+0-1966) were made using one-way analysis of 
variance (ANOVA), followed by Tukey's post-hoc comparisons. Significance levels were set at $p<0.05$ for all statistical analyses, and results are reported as the mean and SEM. All data were analyzed using the GraphPad Prism 5 statistical program.

\section{Results}

\section{Behavioral outcome}

TBI produced significant deficits in locomotor and exploratory behavior (Fig. 1). Sham mice (craniotomy only) did not show any significant functional differences compared to naïve mice on any behavioral tests. Locomotor performance and exploratory behavior were significantly improved in mice receiving 0-1966 ( $\mathrm{CB}_{2} \mathrm{R}$ agonist) compared to vehicle-treated mice at $48 \mathrm{~h}$ post-TBI (Fig. 1). Rotarod latencies for TBI mice treated with vehicle were significantly reduced compared to sham mice $(p<0.001)$, indicating substantial deficits in balance and coordination (Fig. 1A). Treatment with 0-1966 improved performance on the rotarod compared to vehicletreated mice $(p<0.01)$. Deficits in usage of the affected forelimb were significantly greater in TBI mice treated with vehicle compared to sham mice $(p<0.001)$, while treatment with 0-1966 improved usage of the affected forelimb after TBI compared to vehicle alone $(p<0.01$; Fig. 1B). Open-field exploratory activity (rearing) was significantly reduced in TBI mice treated with vehicle compared to sham mice $(p<0.001$; Fig. 1C). Treatment with 0-1966 promoted normal exploratory activity after TBI compared to vehicle-treated mice $(p<0.01)$.

\section{Edema and substance $P$}

Cerebral edema (percent water content) was significantly greater in TBI mice treated with vehicle compared to sham animals $(p<0.001$; Fig. 2A). Treatment with 0-1966 significantly reduced edema compared to vehicle-treated mice $(p<0.01)$. Although substance P immunoreactivity increased throughout several areas of the brain after injury, including but not limited to the cerebral cortex, thalamus, and spinal trigeminal tract in the brainstem, assessment of substance $P$ was limited to the cerebral cortex (Figs. 2B, 3, and 4). The number of perivascular/parenchymal substance P-immunoreactive areas within the ipsilateral cerebral cortex was significantly greater in TBI mice treated with vehicle compared to sham animals $(p<0.01)$, while $0-1966$ attenuated substance
$\mathrm{P}$ immunoreactive product compared to vehicle alone $(p<0.05$; Fig. 2B and 3).

\section{Macrophage/microglial activation}

The number of Iba1-positive cells and activated macrophage/microglia morphology in the injured hemisphere was significantly greater for TBI mice treated with vehicle compared to sham animals $(p<0.001$; Figs. $5-7)$. Treatment with 0-1966 significantly reduced the number of ipsilateral activated macrophages/microglia compared to vehicle-treated mice ( $p<0.001$; Fig. 5). Microscopic examination under low magnification revealed TBI mice treated with vehicle had increased Iba1-immunoreactive product, number of Iba1-positive cells, tissue swelling, and a greater area of tissue damage (necrotic zone; Fig. 6). Examination under high magnification revealed that vehicle-alone brains had more cells showing an activated morphology characterized by an amoeboid shape with retracted/shortened processes compared to the thinner, highly-branched processes seen in the control and 0-1966 brains (Fig. 7). At the medial border of the craniotomy, injured and sham animal cerebral cortices demonstrated minimal microglial activation in the craniotomized hemisphere; however, there was no significant difference in macrophage/microglia activation between the contralateral hemisphere and sham brains.

\section{Discussion}

The present study shows that $\mathrm{CB}_{2} \mathrm{R}$ activation results in improved locomotor function and exploratory activity in a murine model of TBI. Furthermore, these improvements in functional outcome are associated with a reduction in cerebral edema, reduced perivascular substance P immunoreactivity, and diminished macrophage/microglial activation in the injured brains at $48 \mathrm{~h}$ post-injury.

\section{Effects on neurogenic inflammation: Cerebral edema and neurotransmitter and cellular responses}

Our results are consistent with those reported by Donkin and colleagues, indicating that TBI leads to substantial increases in perivascular substance P immunoreactivity (Donkin et al., 2009). Perivascular substance $P$ immunoreactivity was found to clearly outline the cerebral vasculature, while also appearing in its unbound punctate form within the paren-

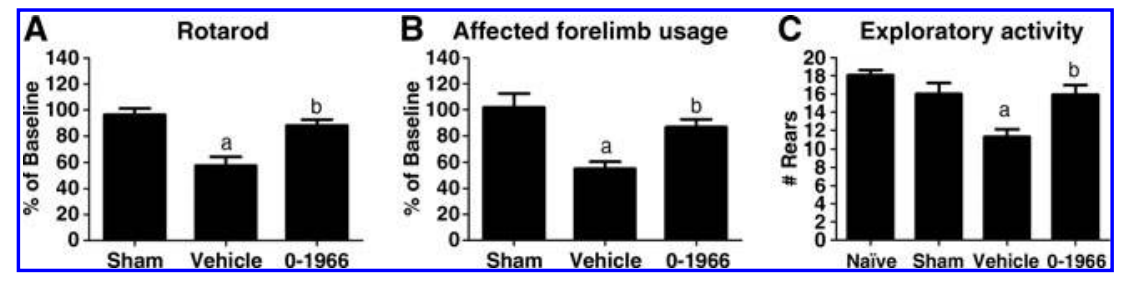

FIG. 1. Effects of the cannabinoid-2 receptor $\left(\mathrm{CB}_{2} \mathrm{R}\right)$ agonist 0-1966 on rotarod, forelimb cylinder, and open-field exploration tests at $48 \mathrm{~h}$ after traumatic brain injury (TBI). Treatment with 0-1966 improved performance on the rotarod (A) where (a) represents a significant difference between vehicle-treated mice and naïve and sham controls $(p<0.001$ and $p<0.01$, respectively), and (b) represents a significant difference between mice receiving 0-1966 and vehicle9treated mice $(p<0.01)$. Treatment with 0-1966 increased the usage of the affected forelimb (B), where (a) represents a significant difference between vehicle-treated and sham mice $(p<0.001)$, and $(\mathbf{b})$ represents a significant difference between mice receiving 0-1966 and vehicle $(p<0.01)$. Treatment with $0-1966$ promoted exploratory/rearing activity $(\mathbf{C})$, where (a) represents a significant difference between vehicle- and sham-treated mice $(p<0.001)$, and $(\mathbf{b})$ represents a significant difference between mice receiving 0-1966 and vehicle-treated mice $(p<0.01$; naïve $n=20$, sham $n=7$, vehicle $n=10$, and 0-1966 $n=10)$. 


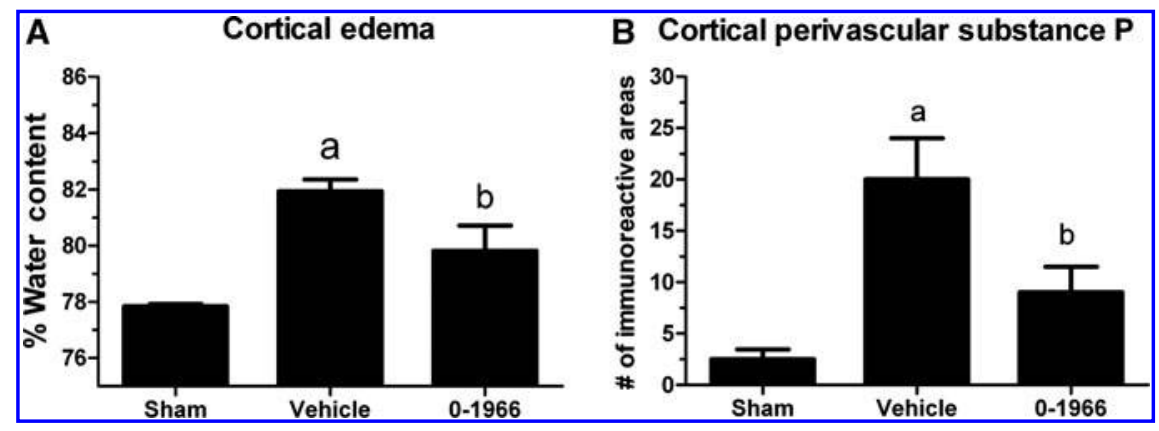

FIG. 2. Effects of the cannabinoid-2 receptor agonist 0-1966 on cortical edema (A), and perivascular/parenchymal substance P immunoreactive product (B), at $48 \mathrm{~h}$ after traumatic brain injury (TBI). Percent water content was significantly greater in the vehicle-treated mice compared to sham animals $(p<0.001$; a). Figure $2 \mathrm{~A}$ shows that treatment with 0 -1966 significantly reduced the percent water content compared to vehicle-treated mice $(p<0.01 ; \mathbf{b})$. Results are expressed as mean percent water content \pm standard error of the mean [SEM]; sham $n=7$, vehicle $n=6$, and 0-1966 $n=4$ ). Figure $2 \mathrm{~B}$ shows that TBI significantly increased the number of perivascular/parenchymal substance P-immunoreactive areas within the ipsilateral cerebral cortex in vehicle-treated mice compared to sham animals $(p<0.01$; a), that was attenuated in the 0-1966-treated group ( $p<0.05 ; \mathbf{b}$; results are expressed as mean number of immunoreactive areas \pm SEM; $n=4 /$ group).

chyma. Substance P also appeared bound to plasma membranes of cells morphologically identified as neurons and astrocytes; however, microglia could not be ruled out. Numerous studies have shown that activated sensory fibers release substance $P$ perivascularly, which then subsequently binds to local glial and neuronal cells (Black, 2002; Donkin et al., 2009; Marriott and Bost, 1998; Severini et al., 2002). Substance P is a potent vasogenic neuropeptide from the tachykinin family that is released as a result of mechanical, chemical, and electrical stimulation of sensory neuron C-fibers (Black, 2002; Donkin et al., 2007; Severini et al., 2002). Cerebral and meningeal blood vessels receive a dense supply of sensory afferents that release substance P when stimulated, whereby changes in blood flow and intracranial pressure promote its release. Previously, in a model of chronic peripheral nerve injury, our laboratory showed substance $\mathrm{P}$ to be increased in the parenchyma and microvasculature of the dorsal horn of the spinal cord following repeated mechanical trauma (Elliott et al., 2008a, 2009a, 2009b; Elliott et al., 2010). Although multiple tachykinins, such as calcitonin-gene related peptide, play a role in the formation of cerebral edema, substance $P$ is clearly the primary contributor to the development of increased vascular permeability and plasma extravasation. Furthermore, substance P alters osmotic gradients and has been implicated in mediating transient blood-brain barrier disruption after TBI (Donkin et al., 2009).

There is a wealth of evidence to suggest that substance $\mathrm{P}$ promotes the inflammatory response through additional pathways. For instance, there is a significant amount of data implicating substance $\mathrm{P}$ as a primary mediator of gliosis. The importance of substance $P$ in regulating gliosis in the injured CNS by mediating microglial and astrocyte activation and the release of proinflammatory mediators such as cytokines, prostaglandins, thromboxane $\mathrm{B}_{2}$, and superoxide ions, cannot be overlooked (Black, 2002; Donkin et al., 2007; Palma et al., 1997). Substance P receptors are found on non-neuronal cells, including astrocytes, lymphocytes, leukocytes, macrophages, and mast cells. Substance P binding can stimulate these cells to produce proinflammatory cytokines such as IL-1, IL-6, and TNF- $\alpha$ (Black, 2002; Lin, 1995; Marriott and Bost, 1998). Substance $\mathrm{P}$ has also been shown to downregulate the synthesis of transforming growth factor (TGF), a polypeptide with anti-inflammatory properties (Marriott and Bost, 1998). TGF anti-inflammatory actions are mediated by inhibiting monocyte-derived phagocytes and lymphocytes. Furthermore,
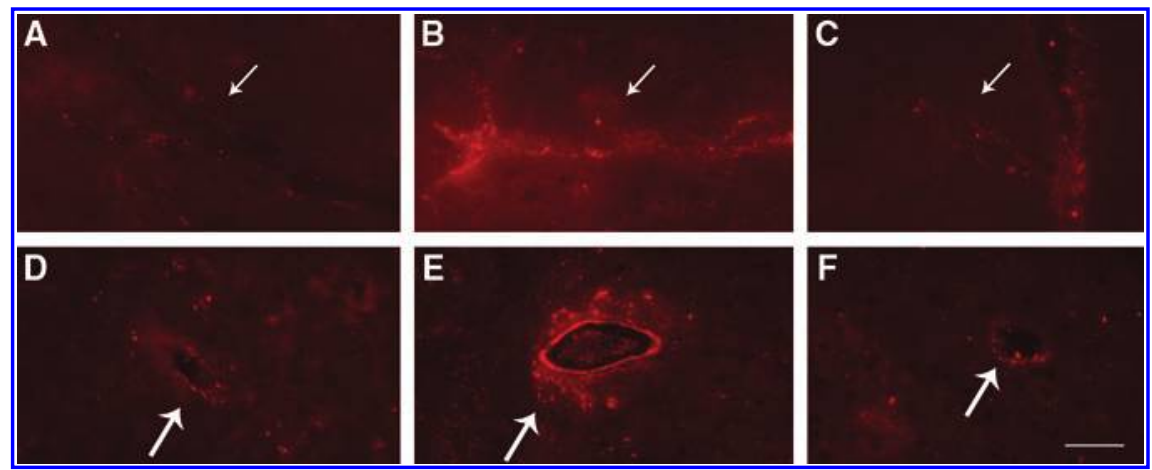

FIG. 3. Micrographs showing substance P immunofluorescence surrounding cerebral blood vessels with longitudinal (AC), and transverse (D-F) orientations. Minimal perivascular staining is seen in the brains of sham mice (A and D). Traumatic brain injury (TBI) mice treated with vehicle (B and $\mathbf{E})$ have substantial perivascular substance P immunostaining, while TBI mice treated with the cannabinoid-2 receptor agonist 0-1966 show a reduction in perivascular substance $P$ immunostaining (C and F; scale bar $=100 \mu \mathrm{m}$; arrows indicate blood vessels). 

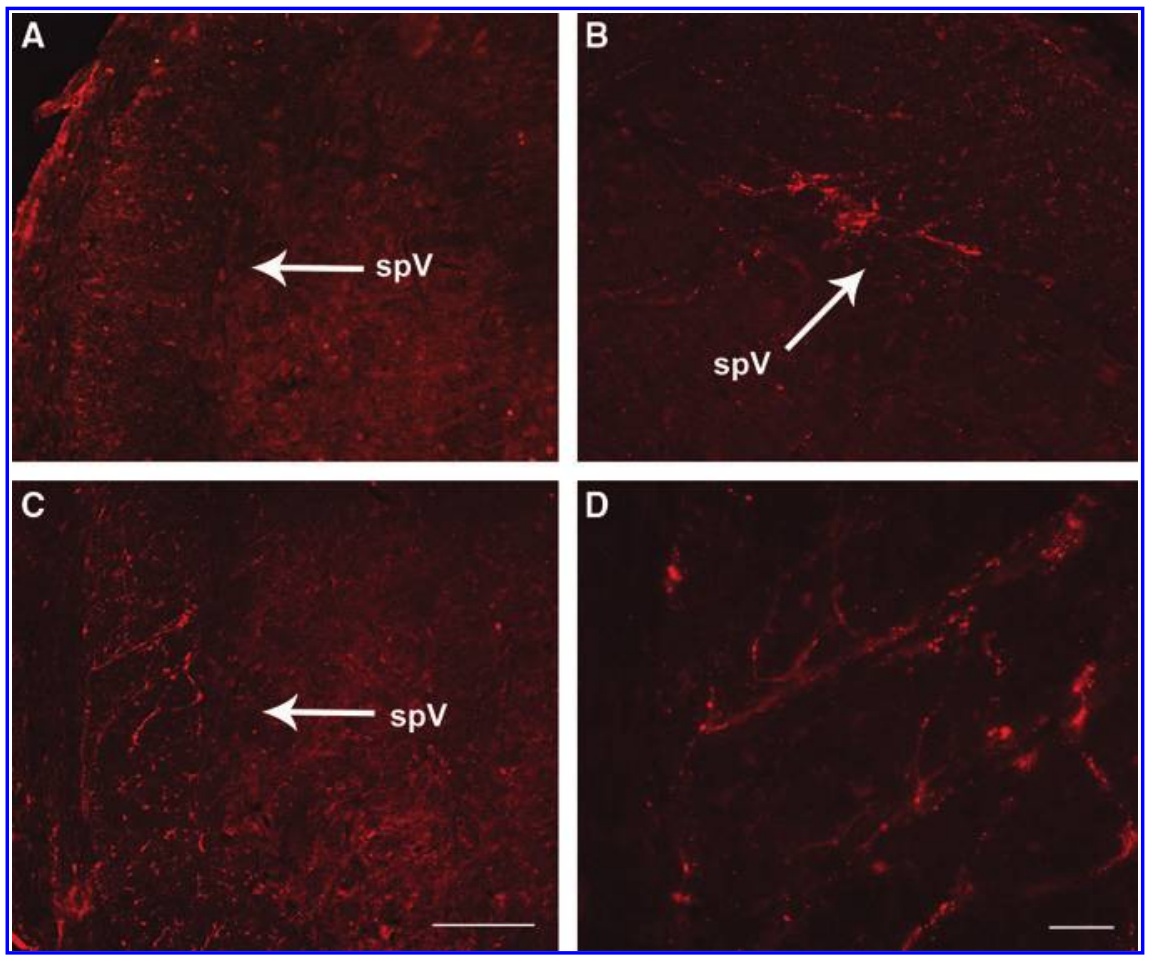

FIG. 4. Micrographs showing substance $\mathrm{P}$ immunofluorescence within the brainstem spinal trigeminal tract (spV), which appears to be mostly bound to axons or dendrites, with very little staining of neuronal cell bodies. Negligible staining was found in a normal control brain (A). Substance P immunostaining was found in the contralateral (B) and ipsilateral hemispheres (C and D), with greater immunostaining seen ipsilateral to the injury. Images $\mathbf{A}-\mathbf{C}$ were captured with a $20 \times$ objective, and image $\mathbf{D}$ with a $60 \times$ objective (scale bar $=50 \mu \mathrm{m}$ in $\mathbf{A}-\mathbf{C}$, and $10 \mu \mathrm{m}$ in D).

degradation of substance $\mathrm{P}$ is a slow process, which allows for a prolonged presence of the neurotransmitter (Severini et al., 2002). Therefore, the contribution of substance $P$ to gliosis and inflammatory cascades may prolong and exacerbate secondary damage after TBI.

\section{$\mathrm{CB}_{2} \mathrm{R}$ modulation}

Currently there is a paucity of pre-clinical data regarding endocannabinoid-mediated modulation of the post-TBI in- flammatory response. Our work represents the first study of selective $\mathrm{CB}_{2} \mathrm{R}$ modulation in TBI. Recent recognition of the immunomodulatory properties of the $\mathrm{CB}_{2} \mathrm{R}$ has led to increasing focus on this receptor as a therapeutic target in many models of neuronal injury and neurodegenerative disease. Growing evidence supports the theory that $C_{2} R$ agonists modulate microglial activity such as chemotaxis and production of proinflammatory cytokines (Cabral et al., 2008; Cabral and Griffin-Thomas, 2009). Microglia $\mathrm{CB}_{2} \mathrm{R}$ expression is negligible at rest and highest during primed

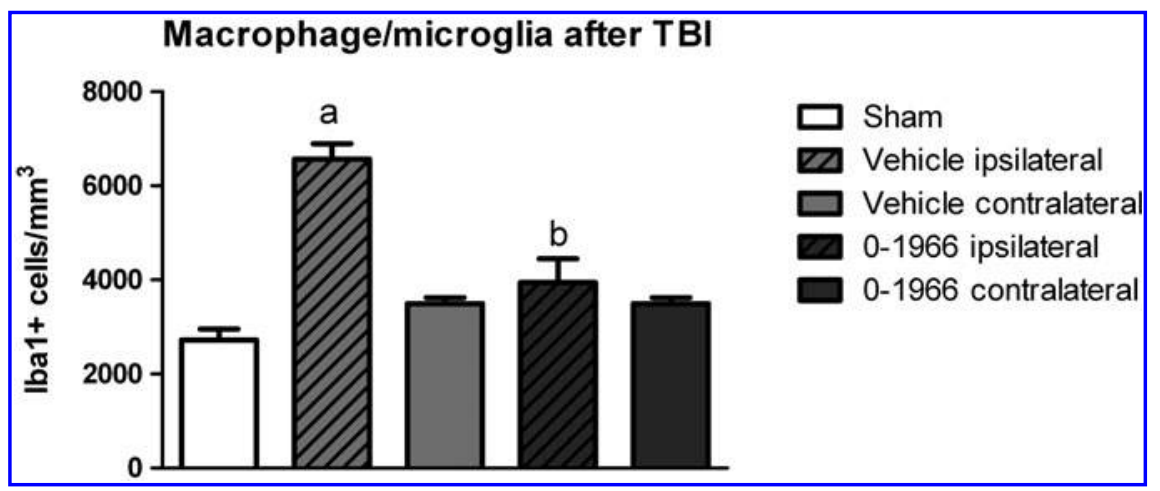

FIG. 5. Effects of the cannabinoid-2 receptor agonist 0-1966 on the number of peri-lesional macrophage/microglia cells at $48 \mathrm{~h}$ after traumatic brain injury (TBI). The number of macrophages/microglia was significantly greater in the vehicle-treated mice compared to sham animals $(p<0.001 ;$ a). Treatment with 0-1966 significantly reduced the number of macrophages/ microglia compared to vehicle-treated mice $(p<0.001 ; \mathbf{b})$. Results are expressed as mean ionizing calcium-binding adaptor molecule (Iba1)-positive cells $/ \mathrm{mm}^{3} \pm$ standard error of the mean; sham $n=5$, vehicle $n=7$, and 0-1966 $n=7$ ). 


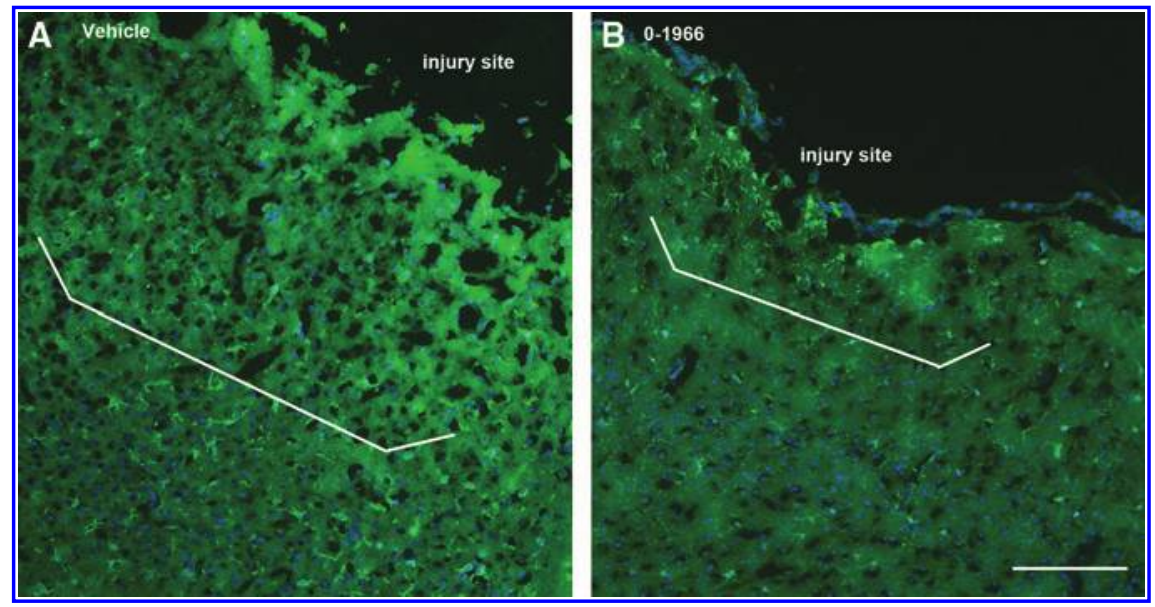

FIG. 6. Low-magnification $(10 \times$ objective) micrograph shows traumatic brain injury (TBI) brains for vehicle-treated animals (A), and animals receiving 0-1966 (B). The vehicle-treated brain (A) has increased ionizing calcium-binding adaptor molecule (Iba1)-immunoreactive product and more of Iba1-positive cells, tissue swelling, and a greater area of tissue damage (necrotic zone), delineated by the white brackets, compared to the mice receiving the cannabinoid-2 receptor agonist 0-1966 (B; scale bar $=100$ micrometers).

and activated states such as those occurring after injury, indicating its relevance in neuroimmune function (Cabral et al., 2008). It is hypothesized that the role of microglial $\mathrm{CB}_{2} \mathrm{R}$ activity is predominantly anti-inflammatory (Carrier et al., 2005). Our finding that a $\mathrm{CB}_{2} \mathrm{R}$ agonist reduced edema and substance $\mathrm{P}$ immunoreactivity, as well as dampening the immune cell response to TBI, supports this hypothesis and the anti-inflammatory effects we have reported in our other CNS injury models. Previously, using real-time RTPCR, our laboratory found increased expression of the $\mathrm{CB}_{2} \mathrm{R}$ in a model of traumatic spinal cord injury (Baty et al., 2008). In the same study, we showed that treatment with the $\mathrm{CB}_{2} \mathrm{R}$ agonist reduced TNF- $\alpha$ mRNA expression. Our laboratory also found that $\mathrm{CB}_{2} \mathrm{R}$ activation reduced white blood cell rolling and adhesion, adhesion molecule expression, immune cell infiltration, and macrophage activation, in a model of cerebral ischemia (Zhang et al., 2007, $2009 a, 2009 b) . C_{2} R$ activation has also been shown to decrease the activity of antigen-presenting cells, and to downregulate cytokine (IFN- $\gamma$ and TNF- $\alpha$ ) production following inflammatory stimuli (Berdyshev, 2000; Klein and Cabral, 2006; Lombard et al., 2007; Walter and Stella, 2004).
Evidence that microglial $\mathrm{CB}_{2} \mathrm{R}$ activity is predominantly anti-inflammatory is also suggested by results obtained using a non-selective CBR agonist, 2-arachidonoyl glycerol (2-AG). In a study by Panikashvili and associates, the cannabinoid 2$A G$, which has both $C_{1} R$ - and $C_{2} R$-mediated neuroprotection following head injury, was associated with inhibition of NF- $\kappa$ B, TNF- $\alpha$, IL-1B, and IL-6, as well as attenuated bloodbrain barrier damage (Panikashvili et al., 2005, 2006). In an in vitro study, $2-\mathrm{AG}$ reduced macrophage-derived TNF- $\alpha$ and reactive oxygen species after LPS stimulation (Gallily et al., 2000). Studies also showed that $2-A G$ elicited neuroprotection after closed head injury, which was reversed by a $C_{1} R$ antagonist, while $\mathrm{CB}_{1} \mathrm{R}-\mathrm{knock}$ out mice showed poorer outcomes from TBI. (Panikashvili et al., 2001, 2005, 2006). Investigators acknowledge the non-selectivity of high dosages of $\mathrm{CB}_{1} \mathrm{R}$ antagonists, and the fact that $\mathrm{CB}_{1} \mathrm{R}$-knockout mice appear to be neurologically compromised prior to injury may confound findings. In addition, it has been hypothesized that 2-AG exerts vasorelaxant actions that may be important for regulating cerebrovascular function in the injured brain (Chen et al., 2000). Chen and associates reported that 2-AG modulates human brain capillary and microvascular responses to the potent vasoconstrictor endothelin-1, with implications

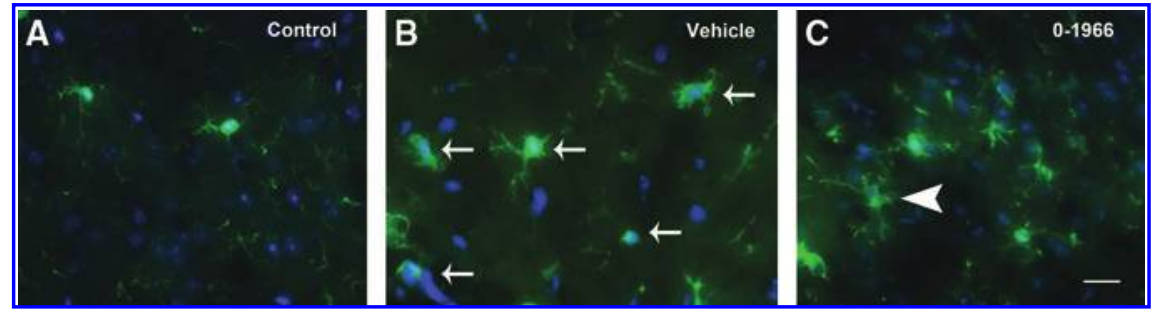

FIG. 7. High-magnification $(60 \times$ objective) micrograph shows ionizing calcium-binding adaptor molecule (Iba1)-positive macrophages/microglia, and 4,6-diamino-2-phenylindole (DAPI)-immunofluorescent cells in uninjured animals (A), vehicletreated animals (B), and animals receiving the cannabinoid-2 receptor agonist 0-1966 (C). The vehicle-treated brain has a greater number of cells showing an activated morphology, characterized by an amoeboid shape with retracted/shortened processes (arrows in B), compared to the highly-branched processes in the control animals (A) and animals receiving 0-1966 (arrowhead in C). 
for a $\mathrm{CB}_{1} \mathrm{R}$-mediated mechanism (Chen et al., 2000). Although studies indicate that the $\mathrm{CB}_{1} \mathrm{R}$ may have neuroprotective mechanisms after TBI, the involvement of the $\mathrm{CB}_{2} \mathrm{R}$ and other receptors yet to be discovered cannot be excluded by these studies. In sum, our results and those of others provide evidence that modulation of the macrophage/microglial response to TBI is a potential therapeutic strategy (Bye et al., 2007; Shein et al., 2008).

\section{Future implications}

At present, the mechanisms by which cannabinoids participate in neuroprotection following TBI are poorly understood. Hypothermia, anti-excitotoxicity, reduced calcium influx, anti-inflammatory and antioxidant activity, inhibited endothelin-1 vasoconstriction, and blood-brain barrier protection, have all been proposed as potential mechanisms of this protection (van der Stelt et al., 2002). The prospect that endocannabinoids may work via multiple mechanisms may be comparable to current therapeutic compounds used in clinical trials like progesterone. Clearly, additional exploration into the role of the endocannabinoid system in the modulation of the post-TBI inflammatory response is needed. Additionally, further studies are needed to determine whether the immunomodulatory effects of $\mathrm{CB}_{2} \mathrm{R}$ activation lead to lasting neuroprotective effects and improvements in behavioral outcome.

\section{Conclusions}

In conclusion, our results indicate that the effects of a selective $\mathrm{CB}_{2} \mathrm{R}$ agonist, 0-1966, on neuroinflammatory responses, including cerebral edema, substance $\mathrm{P}$ immunoexpression, and macrophage/microglial activation, contribute to recovery of acute deficits in motor function and exploratory activity. These results demonstrate the importance of immune-endocannabinoid system interactions in the traumatized brain, along with the therapeutic actions of selective modulation of the $\mathrm{CB}_{2} \mathrm{R}$.

\section{Acknowledgments}

We are extremely appreciative of the major contributions made by Karena Browne, particularly in the area of behavior, and for the help provided by Dr. Judith Litvin with respect to immunohistochemistry.

\section{Author Contributions}

Experimental design and oversight was by Dr. Melanie Elliott. The experiments were conducted by Dr. Melanie Elliott, Dr. Peter Amenta, and Karena Browne. Data analysis, interpretation, and manuscript preparation were by Drs. Melanie Elliott, Jack Jallo, Mary Barbe, and Ronald Tuma. Experimental agents and analytical tools were contributed by Drs. Ronald Tuma and Mary Barbe.

\section{Author Disclosure Statement}

No competing financial interests exist.

\section{References}

Baskaya, M.K., Dogan, A., Temiz, C., and Dempsey, R.J. (2000). Application of 2,3,5-triphenyltetrazolium chloride staining to evaluate injury volume after controlled cortical impact brain injury: role of brain edema in evolution of injury volume. J. Neurotrauma 17, 93-99.

Baskin, Y.K., Dietrich, W.D., and Green, E.J. (2003). Two effective behavioral tasks for evaluating sensor motor dysfunction following traumatic brain injury in mice. J. Neurosci. Methods 129, 87-93.

Baty, D.E, Zhang, M., Li, H., Erb, C.J., Adler, M.W., Ganea, D., Loftus, C.M., Jallo, J.I., and Tuma, R.F. (2008). Cannabinoid CB2 receptor activation attenuates motor and autonomic function deficits in a mouse model of spinal cord injury. $\underline{\text { Clin. }}$ Neurosurg. 55, 172-177.

Berdyshev, E.V. (2000). Cannabinoid receptors and the regulation of immune response. Chem. Phys. Lipids 108, 169-190.

Black, P.H. (2002). Stress and the inflammatory response: a review of neurogenic inflammation. Brain Behav. Immun. 16, 622-653.

Bye, N., Habgood, M.D., Callaway, J.K., Malakooti, N., Potter, A., Kossmann, T., and Morganti-Kossmann, M.C. (2007). Transient neuroprotection by minocycline following traumatic brain injury is associated with attenuated microglial activation but no changes in cell apoptosis or neutrophil infiltration. Exp. Neurol. 204, 220-233.

Cabral, G.A., and Griffin-Thomas, L. (2009). Emerging role of the cannabinoid receptor CB2 in immune regulation: therapeutic prospects for neuroinflammation. Expert Rev. Mol. Med. 11, e3.

Cabral, G.A., Raborn, E.S., Griffin, L., Dennis, J., and MarcianoCabral, F. (2008). CB2 receptors in the brain: role in central immune function. Br. J. Pharmacol. 153, 240-251.

Carrier, E.J., Patel, S., and Hillard, C.J. (2005). Endocannabinoids in neuroimmunology and stress. Curr. Drug Targets CNS Neurol. Disord. 4, 657-665.

Chen, Y., McCarron, R.M., Ohara, Y., Bembry, J., Azzam, N., Lenz, F.A., Shohami, E., Mechoulam, R., and Spatz, M. (2000). Human brain capillary endothelium: 2-arachidonoglycerol (endocannabinoid) interacts with endothelin-1. Circ. Res. 87, 323-327.

Donkin, J.J., Nimmo, A.J., Cernak, I., Blumbergs, P.C., and Vink, R. (2009). Substance P is associated with the development of brain edema and functional deficits after traumatic brain injury. J. Cereb. Blood Flow Metab. 29, 1388-1398.

Donkin, J.J., Turner, R.J., Hassan, I., and Vink, R. (2007). Substance P in traumatic brain injury. Prog. Brain Res. 161, 97-109.

Elliott, M.B., Barr, A.E., and Barbe, M.F. (2009a). Spinal substance $\mathrm{P}$ and neurokinin-1 increase with high repetition reaching. Neurosci. Lett. 454, 33-37.

Elliott, M.B., Barr, A.E., Clark, B.D., Amin, M., Amin, S., and Barbe, M.F. (2009b). High force reaching task induces widespread inflammation, increased spinal cord neurochemicals and neuropathic pain. Neuroscience 158, 922-931.

Elliott, M.B., Jallo, J.J., Barbe, M.F., and Tume, R.F. (2009c). Hypertonic saline attenuates tissue loss and astrocyte hypertrophy in a model of traumatic brain injury. Brain Res. 1305, 183-191.

Elliott, M.B., Barr, A.E., Clark, B.D., Wade, C.K., and Barbe, M.F. (2010). Performance of a repetitive task by aged rats leads to median neuropathy and spinal cord inflammation with associated sensorimotor declines. Neuroscience 170, 929-941.

Elliott, M.B., Jallo, J.J., and Tuma, R.F. (2008b). An investigation of cerebral edema and injury volume assessments for controlled cortical impact injury. J. Neurosci. Methods 168, 320-324. 
Elliott, M.B., Jallo, J.J., Gaughan, J.P., and Tuma, R.F. (2007). Effects of crystalloid-colloid solutions on traumatic brain injury. J. Neurotrauma 24, 195-202.

Elliott, M.B., Barr, A.E., Kietrys, D.M., Al-Shatti, T., Amin, M., and Barbe, M.F. (2008a). Peripheral neuritis and increased spinal cord neurochemicals are induced in a model of repetitive motion injury with low force and repetition exposure. Brain Res. 1218, 103-113.

Gallily, R., Breuer, A., and Mechoulam, R. (2000). 2-Arachidonylglycerol, an endogenous cannabinoid, inhibits tumor necrosis factor-alpha production in murine macrophages, and in mice. Eur. J. Pharmacol. 406, R5-R7.

Gong, J.P., Onaivi, E.S., Ishiguro, H., Liu, Q.R., Tagliaferro, P.A., Brusco, A., and Uhl, G.R. (2006). Cannabinoid CB2 receptors: immunohistochemical localization in rat brain. Brain Res. 1071, 10-23.

Kawamata, T., and Katayama, Y. (2007). Cerebral contusion: a role model for lesion progression. Prog. Brain Res. 161, 235-241.

Kingery, W.S., Offley, S.C., Guo, T.Z., Davies, M.F., Clark, J.D., and Jacobs, C.R. (2003). A substance P receptor (NK1) antagonist enhances the widespread osteoporotic effects of sciatic nerve section. Bone 33, 927-936.

Klein, T.W., and Cabral, G.A. (2006). Cannabinoid-induced immune suppression and modulation of antigen-presenting cells. J. Neuroimmune Pharmacol. 1, 50-64.

Lin, R.C. (1995). Reactive astrocytes express substance-P immunoreactivity in the adult forebrain after injury. Neuroreport 7, 310-312.

Lombard, C., Nagarkatti, M., and Nagarkatti, P. (2007). CB2 cannabinoid receptor agonist, JWH-015, triggers apoptosis in immune cells: potential role for CB2-selective ligands as immunosuppressive agents. Clin. Immunol. 122, 259-270.

Marriott, I., and Bost, K.L. (1998). Substance P diminishes lipopolysaccharide and interferon-gamma-induced TGF-beta 1 production by cultured murine macrophages. Cell Immunol. $183,113-120$.

Mechoulam, R., and Shohami, E. (2007). Endocannabinoids and traumatic brain injury. Mol. Neurobiol. 36, 68-74.

Mouton, P.R. (ed.) (2002). Principles and Practices of Unbiased Stereology. The Johns Hopkins University Press: Baltimore.

Munro, S., Thomas, K.L., and Abu-Shaar, M. (1993). Molecular characterization of a peripheral receptor for cannabinoids. Nature 365, 61-65.

Okiyama, K., Smith, D.H., Gennarelli, T.A., Simon, R.P., Leach, M., and McIntosh, T.K. (1995). The sodium channel blocker and glutamate release inhibitor BW1003C87 and magnesium attenuate regional cerebral edema following experimental brain injury in the rat. J. Neurochem. 64, 802-809.

Onyszchuk, G., Al-Hafez, B., He, YY., Bilgen, M., Berman, N.E., and Brooks, W.M. (2007). A mouse model of sensorimotor controlled cortical impact: characterization using longitudinal magnetic resonance imaging, behavioral assessments and histology. J. Neurosci. Methods 160, 187-196.

Palma, C., Minghetti, L., Astolfi, M., Ambrosini, E., Silberstein, F.C., Manzini, S., Levi, G., and Aloisi, F. (1997). Functional characterization of substance $\mathrm{P}$ receptors on cultured human spinal cord astrocytes: synergism of substance $\mathrm{P}$ with cytokines in inducing interleukin-6 and prostaglandin E2 production. Glia 21, 183-193.

Panikashvili, D., Mechoulam, R., Beni, S.M., Alexandrovich, A., and Shohami, E. (2005). CB1 cannabinoid receptors are involved in neuroprotection via NF-kappa B inhibition. J. Cereb. Blood Flow Metab. 25, 477-484.
Panikashvili, D., Shein, N.A., Mechoulam, R., Trembovler, V., Kohen, R., Alexandrovich, A., and Shohami, E. (2006). The endocannabinoid 2-AG protects the blood-brain barrier after closed head injury and inhibits mRNA expression of proinflammatory cytokines. Neurobiol. Dis. 22, 257-264.

Panikashvili, D., Simeonidou, C., Ben-Shabat, S., Hanus, L., Breuer, A., Mechoulam, R., and Shohami, E. (2001). An endogenous cannabinoid (2-AG) is neuroprotective after brain injury. Nature 413, 527-531.

Saatman, K.E., Feeko, K.J., Pape, R.L., and Raghupathi, R. (2006). Differential behavioral and histopathological responses to graded cortical impact injury in mice. J. Neurotrauma 23, 1241-1253.

Severini, C., Improta, G., Falconieri-Erspamer, G., Salvadori, S., and Erspamer, V. (2002). The tachykinin peptide family. Pharmacol. Rev. 54, 285-322.

Shein, N.A., Grigoriadis, N., Horowitz, M., Umschwief, G., Alexandrovich, A.G., Simeonidou, C., Grigoriadis, S., Touloumi, O., and Shohami, E. (2008). Microglial involvement in neuroprotection following experimental traumatic brain injury in heat-acclimated mice. Brain Res. 1244, 132-141.

van der Stelt, M., Veldhuis, W.B., Maccarrone, M., Bar, P.R., Nicolay, K., Veldink, G.A., Di Marzo, V., and Vliegenthart, J.F. (2002). Acute neuronal injury, excitotoxicity, and the endocannabinoid system. Mol. Neurobiol. 26, 317-346.

Van Sickle, M.D., Duncan, M., Kingsley, P.J., Mouihate, A., Urbani, P., Mackie, K., Stella, N., Makriyannis, A., Piomelli, D., Davison, J.S., Marnett, L.J., Di Marzo, V., Pittman, Q.J., Patel, K.D., and Sharkey, K.A. (2005). Identification and functional characterization of brainstem cannabinoid CB2 receptors. Science 310, 329-332.

Vink, R., and van den Heuvel, C. (2010). Substance P antagonists as a therapeutic approach to improving outcome following traumatic brain injury. Neurotherapeutics 7, 74-80.

Wagner, A.K., Postal, B.A., Darrah, S.D., Chen, X., and Khan, A.S. (2007). Deficits in novelty exploration after controlled cortical impact. J. Neurotrauma 24, 1308-1320.

Walter, L., and Stella, N. (2004). Cannabinoids and neuroinflammation. Br. J. Pharmacol. 141, 775-785.

Wiley, J.L., Beletskaya, I.D., Ng, E.W., Dai, Z., Crocker, P.J., Mahadevan, A., Razdan, R.K., and Martin, B.R. (2002). Resorcinol derivatives: a novel template for the development of cannabinoid $\mathrm{CB}(1) / \mathrm{CB}(2)$ and $\mathrm{CB}(2)$-selective agonists. I. Pharmacol. Exp. Ther. 301, 679-689.

Zhang, M., Adler, M.W., Abood, M.E., Ganea, D., Jallo, J., and Tuma, R.F. (2009a). CB2 receptor activation attenuates microcirculatory dysfunction during cerebral ischemic/ reperfusion injury. Microvasc. Res. 78, 86-94.

Zhang, M., Martin, B.R., Adler, M.W., Razdan, R.K., Jallo, J.I., and Tuma, R.F. (2007). Cannabinoid CB(2) receptor activation decreases cerebral infarction in a mouse focal ischemia/reperfusion model. J. Cereb. Blood Flow Metab. 27, 1387-1396.

Zhang, M., Martin, B.R., Adler, M.W., Razdan, R.J., Kong, W., Ganea, D., and Tuma, R.F. (2009b). Modulation of cannabinoid receptor activation as a neuroprotective strategy for EAE and stroke. I. Neuroimmune Pharmacol. 4, 249-259.

Address correspondence to: Melanie B. Elliott, Ph.D. Department of Neurosurgery Thomas Jefferson University 1025 Walnut Street Philadelphia, PA 19107

E-mail: melanie.elliott@jefferson.edu 
